\title{
Chemoradiation for Pediatric Primary Cardiac Leiomyosarcoma: Case Report and Review of Literature
}

\author{
James Janopaul-Naylor ${ }^{1}$, Kirk Kanter ${ }^{2}$, Thomas Olson ${ }^{2}$, and Bree Eaton ${ }^{1}$ \\ ${ }^{1}$ Emory University Winship Cancer Institute \\ ${ }^{2}$ Emory University School of Medicine
}

April 23, 2021

\begin{abstract}
A 13-year-old healthy girl presented with dizziness and palpitations, found to have a left atrial mass. An $8 \mathrm{~cm}$ tumor was removed. Pathology confirmed leiomyosarcoma, Grade 3 with positive margins. She was treated with ifosfamide and doxorubicin prior to radiation with concurrent ifosfamide alone. She was treated to 66 Gy in 33 fractions to the operative bed. Prospectively graded toxicities included Gr 2 esophagitis and Gr 1 anorexia, dermatitis and fatigue. She completed a total of 6 cycles of ifosfamide. One year after treatment she had no evidence of disease with normal ECHO and no cardiac, pulmonary or esophageal symptoms.
\end{abstract}

\section{Hosted file}

Cardiac Sarcoma Case Report.pdf available at https://authorea.com/users/409663/articles/ 519258-chemoradiation-for-pediatric-primary-cardiac-leiomyosarcoma-case-report-andreview-of-literature 
Figure 1. Pre-op MRI revealing lobulated mass in left atrium extending through mitral valve and attached to pulmonary veins and proton radiation plan. A) Axial Haste sequence showing lobulated tumor invading left ventricle (star). B) Sagittal STIR sequence showing heterogenous mass in left atrium and left ventricle (arrow). C) Representative CT axial slice of proton radiotherapy plan with anterior heart receiving no radiation dose (star) and scale in Gy. Red line indicating high risk CTV planned to receive $66 \mathrm{~Gy}(\mathrm{RBE})$.
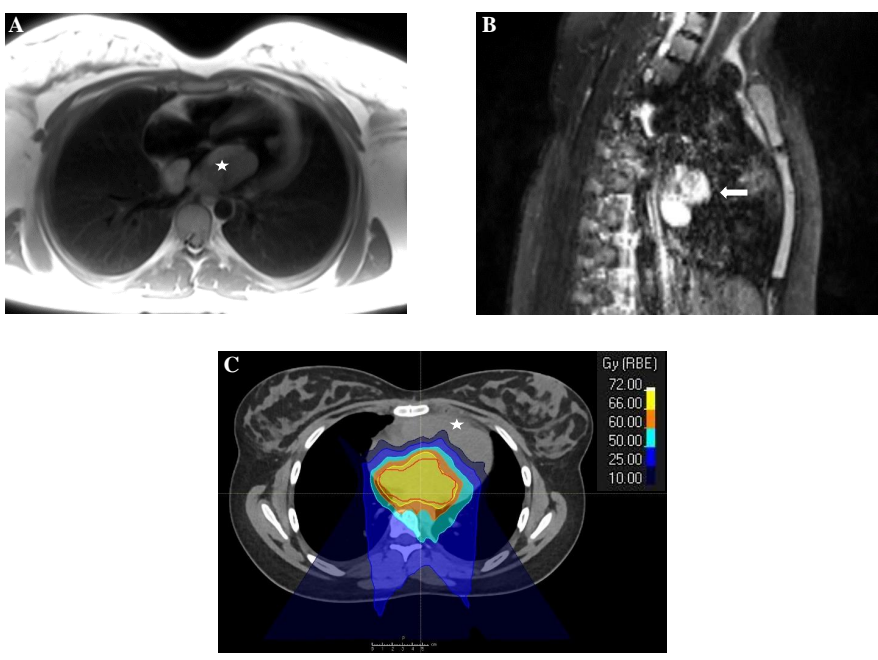

\section{Hosted file}

Table 1.pdf available at https://authorea.com/users/409663/articles/519258-chemoradiationfor-pediatric-primary-cardiac-leiomyosarcoma-case-report-and-review-of-literature 